\title{
Ethnic Disparity in Family Socioeconomic Status in Bangladesh: Implication for Family Welfare Policy Practice
}

\author{
Emaj Uddin
}

Published online: 5 August 2014

(C) Springer International Publishing 2014

\begin{abstract}
Ethnic disparity in family socioeconomic status (FSES) is the social issue across the world societies, including Bangladesh. Based on systematic cross-cultural literature, this paper compares and explains disparity in FSES between the majority (Muslim) and minority ethnic groups (e.g., Hindu, Santal, and Oraon) in Bangladesh. Data in systematic literature reveal that FSES of majority is twofold higher than the minority ethnic groups in Bangladesh. Using social science theories, this paper argues that disadvantaged psychological, social, and political status, including discrimination, and unequal distribution of resources perpetuate disparity in FSES between the majority and minority ethnic groups in Bangladesh. The paper also describes ethnic-sensitive social welfare policy programs on which administrator, educationist, social activist, and social workers may play important roles to reduce, eliminate, and change disparity in FSES between the majority and minority ethnic groups in Bangladesh.
\end{abstract}

Keywords Ethnic disparity · Family socioeconomic status . Social science framework - Majority vs. minority community . Ethnic-sensitive social welfare policy practice $\cdot$ Bangladesh

\section{Introduction}

Family socioeconomic status (e.g., education, occupation, and income) is the building block of social structure in any society. Social science approaches (e.g., biological, social, economic, political, psychological, and cultural) suggest that people

\section{E. Uddin $(\bowtie)$}

Department of Social Work, University of Rajshahi, Rajshahi 6205,

Bangladesh

e-mail: emaj691@yahoo.com

E. Uddin

e-mail: emajmd@yahoo.com across the social systems not only occupy certain socioeconomic position in stratified, hierarchical, and class-based society but also acquire certain power, prestige, privileges, and resources through which they meet their day-to-day human needs and solve personal and social problems faced in a particular society they live. Disparity (also difference) in family socioeconomic status (FSES) between the poor and the rich, between religious/racial/ethnic groups, and even between male and female is the social issue across the world societies, including Bangladesh (Uddin 2009). Over the decades, a number of theoretical approaches and its related systematic comparative studies (Buchmann and Hannum 2001; Breen and Jonsson 2005; Downey 2008; Kao and Thompson 2003; Leicht 2008; Sakamoto et al. 2009) conducted in the USA and EU have revealed that there are wide ethnic disparities in FSES across the societies, although the societies are highly developed, fully democratic, and egalitarian in nature.

This paper focuses on ethnic disparity in family socioeconomic status between the majority and minority groups in Bangladesh. Here, the term majority refers to the number of people greater than the half of the total population with which they dominate and authorize in the sociopolitical structure of society. The term minority refers to the number of people lesser than one third of the total population in which they are dominated by the majority in the sociopolitical structure of a society (Yetman and Steele 1975). Eshleman and Cashion (1985) and Miech and Hauser (2000) have defined socioeconomic status as an assessment of individual, family/group, and ethnic community's education, occupation, and income position within a particular society. From statistical point of view (in measurement sense), the term disparity has been defined as the quantity that separates a group from a reference point on a particular measure of socioeconomic status and health. From social and cultural point of view (in explanation sense) disparity refers to the achievement gaps in socioeconomic status 
between men and women, between the rich and the poor and even between races and ethnic groups associated with brain structure, psychological aspiration, significant others, disadvantaged socioeconomic status, political influence, and culture of poverty in a given geopolitical territories (Eitzen and Zinn 1997). Disparity in family status attainment in this paper refers to the variations in acquiring family socioeconomic status between the majority and minority ethnic groups in connection with their differential socioeconomic position, access in and control over economic and valuable resources, and political power in stratified social structure (Ogbu 1978).

Functional theory and its comparative research studies have revealed that FSES of people with highly developed capital market economies is higher than that of the people with moderate market and agricultural ones. The functionalists have argued that without achievement of higher socioeconomic status, people in the former cannot fulfill their human needs and cannot solve their human problems faced in that environment than the latter. Based on cultural capital approach by Bourdieu (1977), credential approach by Collins (1979), social class power (under the conflict theory) approach by Marx and Weber, majority-minority paradigm by Eitzen and Zinn (1997), and oppositional cultural theory by Ogbu (1978), cross-cultural/ethnic studies conducted within the (multicultural) societies (for example, USA, UK) showed that FSES also varies across social class, race, ethnic group, and region. Based on the approaches, researchers have argued that the dominant class or racial/cultural group (the White) by dint of their higher status, power, prestige, and privileges always dominates, deprives, and exploits the lower classes or nondominant cultural/ethnic and racial groups (e.g., the Black, Hispanic, Indian American, African) in the society (Adkins and Valsey 2009; Breen and Jonsson 2005; Peek 1979). As a result, FSES of the lower class and minority ethnic/racial groups is widely lower than the dominant group. In line with the hypothesis, several cross-cultural/cross-ethnic research studies in the multicultural societies have also revealed that the FSES the early generation achieved is transformed into the next generation. As the FSES of the minority parents or nondominant groups compared to the majority (dominant) one is two to threefold lower, so their children's are also lower. In addition, further studies have showed that FSES is a cyclical process in which low educational attainment by someone influences his or her low prestige job involvement that in turn influences low income or earnings in the particular family or social system of a society (Covello and Bollen 1979; de Graaf and Kalmijn 2001; Nolan 2000; Rivera-Batiz 2002).

Likely, Bangladesh is a democratic state or society wherein four major religious communities (e. g., Muslim, Hindu, Budhist, and Christian) and over 44 ethnic/tribal groups live side-by-side (Rafi 2006). Prior to her independence (26 March 1971), the state or society has been struggling to enhance economic prosperity, to eradicate inequality, and to strengthen equal sociocultural progress for all people irrespective of age, sex, social class, religion, ethnicity, and region. In so doing, comprehensive social and economic development programs through public and private organizations (both nongovernment organizations and voluntary agencies) since her inception have been launched for the people's socioeconomic progress, basing on its fundamental constitutional rights/values: freedom, democracy, equality, social justice, self-governance, and sovereignty. But over past three decades, several culturespecific (Ali 1998; Jansen 1999; Kayes 1995) and crosscultural studies (Siddiquee 1984) conducted across the subcultures in the country have reported that FSES of the dominant group (Muslim) is higher than the minority groups, including Hindu, Santal, Mahali, and Oraon and others in the northern region and all over Bangladesh. These studies have argued that most of the minority groups are the poorest of the poor. Most of them have no land property and even settlement of land (Ali 1998; Das 2011), although the country is based on agriculture. They, irrespective of young men and women, children, and elderly, work as day laborers for the collection of their daily necessities. Ethnic studies have shown that most of the adults are illiterate and many of the children never go to school for their formal learning and most of them never access to formal labor force participation because of no formal educational training and job skills, and likely their annual family income is lower than the dominant groups. Some cross-cultural or cross-ethnic literatures reveal that the minority groups cannot maintain their livelihood according to country's societal goals and means because of their low socioeconomic status and suffer from poverty and health problems in the country (Uddin 2011).

However, social and cultural theories and its comparative or cross-cultural literature reviewed suggest that FSES not only significantly varies from one culture to another but also varies among the subcultures within a given society, like Bangladesh. Although there have been enormous comprehensive comparative or cross-cultural information or facts on FSES across the cultures or subcultures in the market or agricultural economies, there is a paucity of cross-cultural information and its theoretical explanation on disparity in FSES and cross-ethnic-sensitive social welfare policy and services in Bangladesh. The first aim of the paper, therefore, is to organize and describe arguments of social and cultural approaches developed by sociologists, social psychologists, and economists to compare and explain disparity in FSES and their interrelationships between the majority (Muslim) and minority (e.g., Hindu, Santal, and Oraon) communities in Bangladesh. The paper also describes comparative social work policy on which social development workers, policymakers, social activists, educationists, and social workers not only understand but also they may play an important part to improve, reduce, and change disparity in FSES between the majority and minority ethnic communities in which they can 
all meet their human needs, and each of them can properly adapt to the changing social situations in Bangladesh.

\section{Method and Data}

Over the past decades, we identify several advancements in social science theories and its cross-ethnic research literature that may help to explain disparities in FSES in Bangladesh. In so doing, we selected and reviewed relevant articles and books on social science approaches (e.g., individual, group, and ethnic community) published in reputed journals and publishing company. For individual approach, we reviewed biological approach by Spencer, functional approach by Blau and Duncan (1967), Davis (1948), Parsons (1953), and Sorokin (1927); social psychological approach by Heider (1958), Hauser et al. (1982), Lewin (1939), Mead (1934), and Sullivan (1950); and Wisconsin model by Sewell and his collaborators (1957, 1967, 1969, 1970 and Sewell and Hauser 1972, 1975, 1980). For social class approach, we selected and reviewed cultural capital approach by Bourdieu (1977), credential approach by Collins (1979), and concerted cultivation approach by Lareau (2003). And majorityminority paradigm by Eitzen and Zinn (1997) and oppositional cultural theory by Ogbu (1978) for community approach are very popular in the field.

We also reviewed both culture-specific and cross-ethnic articles and books published in international journals and publishing company for deriving necessary information. In doing so, we preferred Uddin's $(2009,2011,2012)$ crossethnic family literature and others (Ali 1998; Das 2011; Kayes 1995; Kispotta 1997; Rahaman 2004) in Bangladesh. The findings of these culture-specific and cross-ethnic studies would help to explain disparities in FSES in this country. Especially, Uddin's $(2009,2012)$ studies conducted in the village Kalna, in Tanore Upazila of Rajshahi district, as well as Rasulpur union, Naogaon, Bangladesh were more relevant to do so because these studies used representative samples from the ethnic communities. The samples selected from the ethnic groups were cross-culturally equivalent for the comparison of family socioeconomic status between the majority and minority communities in this country. These studies (Uddin 2009, 2012) also used semi-structural questionnaire method (with open-ended and close-ended questions) and interview technique and maintained systematic procedure for data collection. In addition, the authors also considered cultural and status factors of both the parties when data were collected (Goodenough 1980). Based on research hypotheses, parametric tests were applied to find out differences in FSES between the majority and minority communities studied. These findings of the studies were more relevant to explain disparities in FSES between the majority and minority groups in Bangladesh.

\section{Approaches to Ethnic Disparity in FSES}

Social inequality and disparity in FSES are the age-old human social problems in human civilization. Why and how much extent inequality/disparities in FSES exist in the social systems: families, groups, ethnic or religious communities, regions, and societies are the long-term debates among the social scientists in the sister disciplines. Actually, systematic research studies on the social issues began in early twentieth century. Since then biologists, sociologists, social psychologists, economists, and even anthropologists in their respective disciplines have developed theoretical frameworks and its related methodologies to study, understand, and explain variations/disparities in FSES across individuals, social groups, or racial/ethnic communities within a particular society and even across the societies (Hauser et al. 1982). Regarding status attainment models, especially biological approach by Spencer, functional approach by Blau and Duncan (1967), Davis (1948), Parsons (1953), Sorokin (1927); cultural capital approach by Bourdieu (1977); credential approach by Collins (1979); social psychological approach by Heider (1958), Hauser et al. (1982), Lewin (1939), Mead (1934), Sullivan (1950), Sewell and his collaborators (1957, 1967, 1969, 1970, Sewell and Hauser 1972, 1975, 1980); concerted cultivation approach by Lareau (2003); and currently majority-minority paradigm by Eitzen and Zinn (1997) and oppositional cultural theory by Ogbu (1978) are very popular in the field. The approaches designed and developed by the social scientists expose different assumptions and arguments and explore evidence on the social issues. The following section describes competing assumptions, arguments, and evidence of the social science approaches that may not only help in understanding variations or disparities in FSES but may also help design cross-cultural social welfare policy and practice to eliminate and change the disparities in FSES that prevailed between the communities.

\section{Individual Approach}

Over the past decades, biologists and social psychologists have studied personal factors that influence achievement of individuals' socioeconomic status attainment. While biologists prefer to explain brain structure, psychologists (also social psychologists) conceptualize learning, motivation, cognition, aspiration, and interpersonal influence in socioeconomic status attainment. Biologists assume that brain structure induces variations in individuals' socioeconomic status attainment. Biological researchers (Gottesman 1968; Herrnstein 1973) following nature-nurture approach, evolutionary theory, and its principles propose that some people are born with superior brain structure (for example, Nobel man, upper class, men, White) - cognition, intelligence, and IQ - but others (for example, Black, women) with inferior ones. They suggest that 
people with higher brain qualities achieve better social status and survive longer than the people with lower ones. In line with this hypothesis, researchers concerned with the achievement gap between genders have cited biological differences, such as brain structure and development, as a possible reason why one gender outperforms the other in certain subjects. For example, a Virginia Tech Study conducted in 2000 examined the brains of 508 children and found that different areas of the brain in girls develop in a different sequence compared to boys (Hanlon et al. 1999). They explain that the differing maturation speed of the brain structure between boys and girls affects how one gender processes better information and performs in educational and occupational attainment than others (Sax 2005).

On the other hand, social psychological theory (Wisconsin Model) assumes that an individual's psychological status (e.g., motivation, aspiration, learning, significant others, mental ability and cognition/consciousness, and location in social structure constraints the range of variations in socioeconomic status attainment). Following this assumption, Duncan (1968) found that early intelligence mediating through the number of sibling, father's socioeconomic status in turn influenced son's later intelligence (path $=.82$ ), education ( $\mathrm{path}=.40$ ), occupation (path $=.50$ ), and earnings (path=.26). Sewell et al. (1969) found that parental socioeconomic status (path $=.288$ ) directly effects a son's educational (path $=.457$ ), occupational (path=.522), and income attainment, mediating other variables (aspiration, mental ability, interpersonal and peer influence, academic performance). Overall, the model explained about the $40-57 \%$ variance in educational, $40-50 \%$ in occupational, and $26 \%$ income status attainment. In addition, Herrnstein and Murray (1994) claimed that average genetic variations in intelligence (IQ) are at the root of racial disparities in socioeconomic achievement. Other researchers criticized that there was no significant difference in inherent cognitive ability between different races that could help to explain the achievement gap, but social and cultural environment causes are at the root of the issue (Dickens 2005; Flynn 1980; Nisbett 1998).

\section{Social Class Approach}

There are several approaches to understand disparities in socioeconomic status attainment across the social groups/ social class. Of the approaches, functionalism is a popular theoretical framework to explain educational attainment in relation to socioeconomic status in a given society. Reviewing over the century literature, functionalists assume that industrialization and technological change demand relatively more knowledgeable, skillful, and qualified manpower to meet functional needs of a society. In so doing, modern education system is adopted and operated to provide skillful manpower to be effective in the society (Blau and Duncan
1967; Davis 1948; Parsons 1953). The principles of functional theory summarized by Collins (1979) reflected that (1) the educational requirements of jobs in the industrialized societies are increased as a result of technological change, (2) formal education provides necessary training for the persons who undertake the highly skillful jobs, and (3) in so doing, people are required to spend longer periods of time for formal education. Following these principles, some literature on educational attainment in the USA and Europe reveals that educational attainment/achievement varies according to social class (e.g., lower, middle, and upper), religion, race/ethnicity, and region. Based on the facts related to education, Blau and Duncan (1967), Davis (1948), and Parsons (1953) hypothesize that social class value and parental socioeconomic status, including race/ethnicity, residence, and locality, influence their children's educational attainment. This basic hypothesis drawn by the functionalists is well-proved in later several researches. For example, Blau and Duncan (1967) in their research found that a father's educational (path=.310) and occupational status (path=.279) had a strongly independent effect on the son's education (path=.440), first job, and occupation (path=.394).

Another approach is a cultural capital approach on which many scholars have studied educational attainment in the USA as a form of social reproduction and stratification. Pierre Bourdieu (1977) presented the idea that education leads to social reproduction in a stratified society, honoring the cultural capital of elite classes. Students who possess the valued cultural capital, according to Bourdieu, are rewarded with high academic achievement. When elite class members enter the workforce, they are channeled into high-paying jobs and powerful positions within the society, while those who did not achieve the same level of academic success fall into subordinate occupations and status levels. By rewarding the desired cultural capital with high academic achievement, upper classes are able and prepared to reach higher levels of educational attainment. Members of the working class, on the other hand, are not rewarded for their cultural capital in schools and are instead socialized for working-class jobs.

Annette Lareau (2003) develops concerted cultivation approach that addresses the factors that lead to social stratification in educational attainment. Lareau's idea of concerted cultivation refers to an active involvement of parents in a child's learning and development experiences by creating and controlling organized activities for their children. According to Lareau, middle-class parents engage in concerted cultivation to teach their children, while lower- and working-class parents do not. Laureau further explains that schools firmly encourage and expect parents to use concerted cultivation as a child-rearing strategy. The child-rearing practices of lower- and working-class families thus do not comply with the standards of educational institutions. As a result, lower- and working-class students develop a sense of 
"distance, distrust, and constraint" in educational institutions, while children of middle-class families gain a sense of entitlement. These differences in child-rearing practices lead to children of lower- and working-class families to lack the necessary life skills that the children of the middle class possess, further isolating them from educational opportunities. Based on Marxian social conflict framework, Randall Collins's credential approach (1979) contributes the idea to the study of class-based differences in educational and occupational status attainment. Collins maintains that public schools are socializing institutions that teach and reward middle-class values of competition and achievement. AngloProtestant elites are selectively separated from other students and place into prestigious schools and colleges, where they are trained to hold positions of power. By teaching middle-class culture through the public education system, the elite class ensures a monopoly over positions of power, while other classes acquire the credentials to compete in a subordinate job market and economy.

\section{Community Approach}

Community approach includes broader social and structural characteristics to explain disparity in socioeconomic status attainment among racial/ethnic groups in a particular society. Of the community approaches majority-minority paradigm by Eitzen and Zinn (1997) and oppositional culture approach by Ogbu (1978) are very popular in the social sciences, especially in sociology. Eitzen and Zinn (1997) in their majorityminority paradigm generally assume that socioeconomic disadvantaged status and further unequal distribution of resources, power, prestige, and presumed worth differentially influence socioeconomic status attainment (the ranked values on dimensions of scarce societal rewards, including educational attainment, occupational status, wages, earnings, household income, and wealth) among racial and ethnic groups in a given society. Based on the assumption, Sakamoto et al. (2009) reviewed vast literature in the USA and found that socioeconomic status attainments of the Black, Hispanic, Indian, and African-American except Asian American were lower than the White. With regard to this, they argue that structural disadvantaged status and further inequality in resources, power, prestige, and presumed worth constrain socioeconomic status attainment for the racial and ethnic groups in the USA.

Rather than view racial/ethnic disparity of socioeconomic attainments as a product of structural disadvantages and unequal distribution of resources, power, and rewards, Ogbu (1978, 1987) developed oppositional culture theory (also known as a cultural-ecological theory) that emphasizes minority groups' agency that contributes to their own culture in opposition to dominant (White) groups' suggestive schooling, occupation, and economic success. The central premise of this theory is that an involuntary minority group's (the Black) historical relationship to the dominant group (the White) plays an important role in shaping the group members' belief about how schooling will pay off. Unlike the voluntary minority groups (Asian American), the involuntary minority groups have experienced historically antagonistic situations (e.g., colonization, conquest, slavery, oppression, discrimination, segregation, exploitation, low socioeconomic status) by the dominant group in the USA in which they tend to compare their situations to the dominant group. Through comparing their situations with the dominant group the involuntary groups (the Blacks) make a sense school efforts, hardworking, diplomas, or higher degrees will not be rewarded and they, in turn, respond in the way that is psychologically protective. And they embrace a collective identity that orients their group in opposition to white-controlled institutions (Ogbu 2004). The theoretical explanation of Ogbu (1978) on racial/ethnic disparities in socioeconomic attainment was well-proved in his later several researches (Ogbu 1987, 1991, 1994, 2003) and others in the USA, UK, Canada, and Japan.

\section{Ethnic Disparity in FSES in Bangladesh}

Ethnic community is a group of people who share the same value system: language, values, beliefs, attitudes, norms, customs, or traditions and accordingly, they behave across the social situations for meeting their human needs. The ethnic communities, Muslim, Hindu, Santal, and Oraon, studied in the paper are socioculturally distinct from each other. The Bangladeshi Muslims are socioeconomically and politically more dominant than the other communities (Uddin 2011). Ethnically, they are mixture of different stocks, with the long traditions of Islamic values, attitudes, beliefs, and ideas, and speak in Bengali language with the mixture of Arabic-Urdu preference. The Hindus are the second largest minority group and speak in Bengali language traced from Hinduism (Sarker 1997). The Santal and the Oraon racially belong to ProtoAustraloid stocks and speak in Austric-Mundary language for the former (Kayes 1995) and Sadri and Kuruk for the later. Religiously, every community mentioned bears and preserves distinct belief system: the Muslims believe in Monotheism, the oneness of God or Tawhid; the Hindus believe in polytheism, Gods and Goddesses, some are males and some are females under the creation of almighty Bhagwan, and both the Santal and Oraon believe in animism, nature worships such as birth, death, illness, Sun, Moon, stars, rain, air, cyclone, and other natural disasters.

Based on their respective fundamental cultural belief systems, the communities interact with each other in agriculture economy for their livelihood (Uddin 2009). About $75 \%$ of people in the communities live in rural subsistent economy in 
which most of them are poor. Minority groups such as the Santal and Oraon are the poorest of the poor. One report indicates that $53 \%$ of the rural people are poor, and there are 55 million food insecure households and $62 \%$ adults are illiterate (Rahaman 2004). It is interesting to note that although main occupation of the rural villagers is agriculture, man-land ratio is very low and most of them are landless or near landless due to the law of inheritance, land fragmentation, and overpopulation. Some reports indicate that about $62 \%$ of the rural households are functionally landless (Toufique and Turton 2002; World Bank 2000). Ethnic studies (Rahaman 2004) show that the minority groups in this country are historically poor, functionally landless, socioculturally deprived, and politically nondominant. These differential sociocultural backgrounds of the majority and minority ethnic groups may influence disparity in family socioeconomic status' attainment in Bangladesh.

\section{Family Educational Status}

Educational attainment is the fundamental aspect of family status attainment in the society. Actually, educational status attainment is a basic criterion not only to acquire a certain social status in the family as well as in the wider community but also to access formal labor force participation and earn money for livelihood in any society. Educational status attainment refers to the timing of formal education/learning recognized by a given society. Relevant cross-cultural research studies (Mazzoni et al. 1999; Nsamenang 2007) have reported that timing of formal education in a particular education system not only varies from one person to another (such as sibling education difference) within a system but also varies among the subcultural groups within a given society. Regarding this social psychological and family system, theorists (Heider 1958; Lewin 1939; Mead 1934; Sullivan 1950) explain that parental socioeconomic background, aspiration, educator's personal motivation, peer group, and cognition are responsible for the variations in educational achievement among the ethnic groups.

Although education at primary level in Bangladesh is universal, most of the rural people and the minority groups (Santal, Oraon) are not motivated for education because of traditional agricultural economic system in which they almost informally learn how to cultivate and plant land. Relevant culture-specific studies (Abdullah 2009; Khanam 2004; Ministry of Primary and Mass Education 2010) have revealed that educational attainment of lower class compared to the middle and high ones is very low. Some ethnic studies (Nath et al. 2005; Uddin 2011) have indicated that the minority groups are illiterate. Other studies (Kispota 1997) have found that average years of Muslim education are higher than the Hindu, Santal, and Oraon because of their higher socioeconomic status, resources, dominance in power structure, and parental aspiration in education. Rahaman (2004) found that most of the Santal and Oraon couples ( $68.53 \%$ for husband and $72 \%$ for wife) compared to the Muslim and Hindu ones (29.66 \% for husband and $40.69 \%$ for wife) never went to school. At both primary and secondary levels, educational attainment of the former was also lower than the latter. Following majority-minority paradigm and structural theory, researchers (Breen and Jonsson 2005; Covello and Bollen 1979; Nolan 2000) clearly argue that parental's low socioeconomic status and aspiration and structural inequality were the main causes not to access educational opportunity and educational attainment for the lower class of Muslim and minority people in the country. Likely, Das (2011) and Rahaman (2004) interpret that most of the minority people such as the Santal and others compared to the dominant group (Muslim) never went to school because of their mass poverty and structural deprivation and cultural penetration to them (such as medium of language for instruction and social distance.

\section{Family Occupational Status}

Occupational attainment is an important aspect of a family status attainment in a given society. Occupational attainment of individual person in an economic system fully depends on his or her educational attainment. With regard to this, relevant researches have revealed that formal education and skill training in any culture are essential requirements to be involved in formal labor force participation. But what type of job a person will involve in depends on his or her level of education achieved. As most of the rural Bangladeshi are illiterate, so they adopt several occupations related to agricultural system. As many of them are landless farmers, so they work as day laborers, including the minority groups, such as Oraon and Santal. Over the decade, several studies (Rahman 1984; Rahaman 2004; Sattar 1984) have revealed that both the adult men and women of the ethnic groups take part in agriculture and in any other fields as manual labor and work outside the family from dawn to dusk as laborers because of their low education, lack of proper skills, landlessness, and mass poverty. On the other hand, division of labor between adult men and women of the Muslim and Hindu community is strictly maintained according to sex norms: only adult men in the communities are the breadwinner of the family. So the men work in agricultural field and other economic sectors. But the women of the Muslim and Hindu do not work on the agricultural field.

Cross-ethnic studies (Uddin 2009) have revealed that most of the Muslim and Hindu husbands (62.07\%) are farmers, while most of the Santal and Oraon couples $(83.92 \%$ for husbands and $90.21 \%$ for wives) are day laborers due to high gender role segregation and lack of education and skill training in business and administrative sectors. Other studies have 
reported that most of the formal jobs in the formal and informal sectors are occupied by the dominant educated groups: Muslim and Hindu. Based on social psychological approach, Sewell et al. (1970) found that occupational attainment (.522) was mediating through educational attainment and other factors (e.g., aspirations, peer group and teacher influence, mental ability, and academic performance). According to functional theory (Blau and Duncan 1967; Collins 1979; Davis 1948; Parsons 1953), researchers argue that although main occupation in this region of Bangladesh is agriculture, most of the minority people are landless and severely poor and they even have no settlement/housing land as are many lower class Muslims and Hindu. As a result, most of the minority people, including both adult and non-adult sexes, are involved in day laboring. In addition, occupational mobility like in many lower class Muslims is very low because of proper and sufficient education, including skill training in rural Bangladesh.

\section{Family Income Status}

Family income depends on their aggregate educational and occupational attainment and other resources. Relevant researches hypothesize that the higher the educational and occupational status, the higher the income attainment (Ganzeboom et al. 1991; Takenoshita 2008). Based on the hypothesis, several cross-cultural studies in multicultural societies have revealed that annual or monthly family income of dominant group (White) is twofold higher than the minority (Black, African-American) groups because of their high educational and occupational attainment. Likewise, culture-specific and cross-cultural studies have found that annual income of the Muslim and Hindu families is higher than the minority families, especially the Santal and Oraon families in both rural and urban Bangladesh because the former have higher education and prestigious job, including land property, business, and other sources of income, compared to the later ones. Other studies (Hossain 2007) compare annual family income between the majority and minority communities. Researchers in their studies have found that most of the minority families compared to the majority groups earn below the living standard in Bangladesh. Based on path analysis, Duncan (1968) found that earnings were significantly correlated with the respondents' socioeconomic status and family socioeconomic origins. Likely, researchers in this country argue that low educational and occupational attainment, unemployment, and landlessness and mass poverty of the Santal and Oraon compared to the Muslim and Hindu are the fundamental predictors on their low annual family income in Bangladesh economy.

\section{Relationship of FSES}

Previous cross-cultural studies have explored that the variable of socioeconomic status attainment, especially education, occupation and income, was consistently interrelated (Kaur and
Kalaramna 2004; Peek 1979). The studies hypothesize that higher the educational status attainment, the higher the job status involvement and likely the higher the income attainment. Following this hypothesis, researchers in Bangladesh (Hossain 2007; Rahaman 2004) have found that educational and occupational status of the Muslim and Hindu are higher than the Santal and Oraon couples, and the annual family income of the former is in turn higher than that of the latter. Using representative samples, Uddin (2009) in his crosscultural studies has explored that higher educational and occupational attainment average annual income of the Muslim families was twofold higher than that of the Santal families being studied. Data in the study (Pearson's correlation coefficients) have revealed that there are significantly positive and inverse relationships between the variables of socioeconomic status attainment at $p<0.01$ level. That is husbands' educational attainment was negatively related to their occupational attainment $\left(r=-.346, p=.000^{*}\right)$, in turn was positively related to annual family income attainment $\left(r=.499, p=.000^{*}\right)$. In addition, wives' educational attainment in turn was negatively related to their occupational attainment $\left(r=-.379, p=.000^{*}\right)$ was positively related to annual family income attainment $\left(r=.399, p=.000^{*}\right)$ between the communities in rural Bangladesh. Following Blau and Duncan (1967), Covello and Bollen (1979), Kaur and Kalaramna (2004), and Swell and Hauser's (1975) argument, Uddin (2009) argues that higher educational and occupational status of the Muslim and Hindu compared to the Santal and Oraon linearly influences annual family income. Are these findings and its theoretical explanation imperative to reduce ethnic disparity in FSES between the majority and minority groups in Bangladesh? How? The following section describes comparative social policy practice to do so.

\section{Conclusion and Implications}

In order to compare and explain family socioeconomic status (FSES) between the majority and minority ethnic communities, we reviewed systematic cross-cultural/ethnic literature abroad and in Bangladesh. Cross-cultural data in the literature suggested that FSES of the majority (the Muslim) were higher than that of the minority (e.g., Hindu, Santal, and Oraon) ethnic groups in Bangladesh. Based on the social science frameworks, we argued that differences in motivation, interpersonal influence, consciousness, low socioeconomic status, inequality, deprivation, and dominance in social structure influenced disparities in FSES between the majority and minority groups in this country. These findings and its social science arguments may have practical implications in family welfare policy program, social work practice, and future cross-ethnic research. 
Family Welfare Policy Implications

First of all, the findings on ethnic disparity in FSES and its social science interpretations may help social policy-makers to design proper ethnic-sensitive family welfare policy and programs to reduce, eliminate, and change disparities in FSES between the majority and minority communities in Bangladesh (van Oorschot 2006). In so doing, the government of Bangladesh and its allied organizations may design comparative family welfare policy and programs, focusing on disparities in FSES between the majority and minority families. In designing comparative family welfare policy, policymakers should consider psychological support (e.g., motivation, consciousness-building, and interpersonal influence), social supports (e.g., economic and educational supports) in educational attainment, and political empowerment in community power structure and societal resource distribution (e.g., recruitment, employment opportunities) in which the minority groups (e.g., Hindu, Santal, and Oraon) with low family socioeconomic status may upwardly progress in social structure of Bangladesh. In designing these supports, they should consider the ethnic communities' cultural patterns and feel needs related to their family socioeconomic status in which they all accept and participate in the family welfare programs (Dockery 2010).

\section{Social Work Implications}

The findings may have implications in social work practice. Based on the culturally sensitive family welfare policy programs, social workers in this country may apply these findings into real practice (Hallinan 1994; Houston and Cambell 2001) to reduce disparity in family socioeconomic status between the majority and minority groups, following social work values: respect and dignity for human beings, communication, self-determination, human justice, and equality. Social practitioners (e.g., social caseworker, social group worker) firmly believe that low family socioeconomic status may block family members' meeting human needs, proper personality, and family development. It also impedes family adjustment to the changing environment. Based on culturally sensitive support programs (e.g., psychological, social, and empowerment) in association with disparity in FSES, social workers may provide psychological resources (e.g., counseling, interpersonal influence, motivation, skill training, and awareness-building to those who are uneducated or reluctant to educational attainment (Houston and Cambell 2001; Khoury-Kassabri 2010). In so doing, social workers must consider family and community cultural pattern, mentioned above. In addition, social workers may also mobilize socioeconomic/material resources to achieve formal and nonformal education and job skill training in which uneducated persons in the families are to be educated, or uneducated skillful persons get a better jobs, and likely their personal and familial income may increase. In addition to these supports, community social worker may empower the ethnic families to get equal opportunities and justice in family socioeconomic status (Eitzen and Zinn 1997; Ogbu 1978, 2004). In so doing, social practitioners may create a socially justified and politically democratic environment in which ethnic minority groups with low family socioeconomic status are equally able to access in and control over community and societal resources and social development programs. In addition, community workers may also apply community psychological approach to change in cultural antagonism, social distance, and intercommunity misunderstanding in the society.

\section{Research Implications}

Although the findings on ethnic disparity in FSES and its related social welfare policy practice between the majority and minority groups in Bangladesh are suggestive, this paper has some limitations on individual, social class/group, and community factors that may influence disparity in family socioeconomic status attainment (Blau and Duncan 1967; Sewell and Hauser 1975) and its related social welfare policy practice between the majority and minority groups in Bangladesh. Future cross-ethnic research, therefore, should be conducted on how individual, family background, and community factors influence family socioeconomic status attainment between the majority and minority ethnic groups in Bangladesh.

Acknowledgments The current author acknowledges those researchers and social scientists whose ideas and information help to develop this paper: Disparity in family socioeconomic status in Bangladesh: implication for family welfare policy practice.

\section{References}

Abdullah, S. (2009). Whose education? whose nation? Exploring the role of government of primary school textbooks of Bangladesh in colonialist forms of marginalization and exclusion of poor and ethnic minority children. Unpublished Master Dissertation. Toronto: University of Toronto.

Adkins, D. E., \& Valsey, S. (2009). Toward a unified stratification theory: structure, genome, and status across human societies. Sociological Theory, 27(2), 99-121.

Ali, A. (1998). The Santals of Bangladesh. Calcutta: The Sabuge Sangah Press.

Blau, P. M., \& Duncan, O. D. (1967). The American occupational structure. New York: Wiley.

Bourdieu, P. (1977). Cultural reproduction and social reproduction. In J. Karabel \& A. H. Halsey (Eds.), Power and ideology in education (pp. 487-511). New York: Oxford University Press. 
Breen, R., \& Jonsson, J. O. (2005). Inequality of opportunity in comparative perspective: recent research on educational attainment and social mobility. Annual Review of Sociology, 13, 223-243.

Buchmann, C., \& Hannum, E. (2001). Education and stratification in developing countries: a review of theories and research. Annual Review of Sociology, 27, 77-102.

Collins, R. (1979). The credential society: a historical sociology of education and stratification. New York: Academic.

Covello, V. T., \& Bollen, K. A. (1979). Status consistency in comparative perspective: an examination of educational, occupational, and income data in nine societies. Social Forces, 58, 528-539.

Das, S. (2011). Indigenous people's access to land in Northern-belt of Bangladesh: a study of the Santal community. Unpublished Master Dissertation. Toronto: University of Toronto.

Davis, K. (1948). Human society. New York: Macmillan.

de Graaf, P. M., \& Kalmijn, M. (2001). Trends in the intergenerational transmission of cultural and economic status. Acta Sociologica, 44, $51-66$.

Dickens, W. T. (2005). Genetic differences and school readiness.

Dockery, A. M. (2010). Culture and wellbeing: the case of indigenous Australians. Social Indicators Research, 99, 315-332.

Downey, D. B. (2008). Black/White differences in school performance: the oppositional culture explanation. Annual Review of Sociology, 34, 107-126.

Duncan, O. D. (1968). Ability and achievement. Eugenics Quarterly, 15, $1-11$.

Eitzen, D. S., \& Zinn, M. B. (1997). Social problems. Boston: Allyn \& Bacon.

Eshleman, J. R., \& Cashion, B. G. (1985). Sociology: an introduction (2nd ed.). Boston: Little, Brown and Company.

Flynn, J. R. (1980). Race, IQ, and Jensen. London: Routledge.

Ganzeboom, H. B. G., Treiman, D. J., \& Ultee, W. C. (1991). Comparative intergenerational stratification research: three generations and beyond. Annual Review of Sociology, 17, 277.302.

Goodenough, W. H. (1980). Ethnographic field techniques. In H. C. Triandis \& J. W. Berry (Eds.), Handbook of cross-cultural psychology, methodology (vol. 12. pp. 45-48). Boston: Allyn and Bacon.

Gottesman, I. I. (1968). Biogenetics of race and class. In M. Deutsch, I. Kats, \& A. R. Jensen (Eds.), Social class, race and psychological development (pp. 11-51). New York: Holt, Rinehart, \& Winston.

Hallinan, M. (1994). Tracking: from theory to practice.

Hanlon, H., Thatcher, R., \& Cline, M. (1999). Gender differences in the development of EEG coherence in normal children. Developmental Neuropsychology, 16(3), 479-506.

Hauser, R. M., Mechanic, D., Haller, A. O., \& Hauser, T. S. (Eds.). (1982). Social structure and behavior. New York: Academic.

Heider, F. (1958). The psychology of interpersonal relations. New York: Wiley.

Herrnstein, R. J. (1973). IQ in the meritocracy. New York: Little, Brown.

Herrnstein, R. J., \& Murray, C. (1994). The bell curve: intelligence and class structure in American life. The Free Press.

Hossain, M. A. (2007). A study on minority influence in the context majority-minority inter-group relations in Bangladesh. Unpublished Ph. D. Dissertation. Rajshahi: Rajshahi University.

Houston, S., \& Cambell, J. (2001). Using critical social theory to develop a conceptual framework for comparative social work. International Journal of Social Welfare, 10, 66-73.

Jansen, E. A. (1999). Rural Bangladesh: competition for scarce resources. Dhaka: University Press Limited.

Kao, G., \& Thompson, J. S. (2003). Racial and ethnic stratification in educational achievement and attainment. Annual Review of Sociology, 29, 417-442.

Kaur, H., \& Kalaramna, A. (2004). Study of interrelationship between home environment, social intelligence and socioeconomic status among males and females. Journal of Human Ecology, 16(2), 137.140 .
Kayes, S. (1995). Cultural change of Santal community of Rajshahi district: an anthropological study. Unpublished M. Phil Dissertation, The Institute of Bangladesh Studies. Rajshahi: University of Rajshahi.

Khanam, R. (2004). Impact of child labor on school attendance and school attainment: evidence from Bangladesh. Available at www. soc.nii.ac.jp.

Khoury-Kassabri, M. (2010). Attitudes of Arab and Jewish mothers towards punitive and non-punitive discipline methods. Child \& Family Social Work, 15, 135-144.

Kispotta, L. (1997). Survey report on the Oraon community of Bangladesh. Dinajpur: Oraon Youth Foundation.

Lareau, A. (2003). Unequal childhoods: class, race, and family life. Berkeley: University of California Press.

Leicht, K. T. (2008). Broken down by race and gender? Sociological explanations of new sources of earnings inequality. Annual Review of Sociology, 34, 237-255.

Lewin, K. (1939). Field theory and experiment in social psychology. American Journal of Sociology, 44, 868-897.

Mazzoni, S. A., Gambrell, L. B., \& Korkeamaki, R.-L. (1999). A crosscultural perspective of early literacy motivation. Reading Psychology, 20(3), 237-253.

Mead, G. H. (1934). Mind, self, and society. Chicago: University of Chicago Press.

Miech, R. A., \& Hauser, R. M., (2000). Socioeconomic status (SES) and health at midlife: a comparison of educational attainment with occupation-based indicators. June 2000. Available at www.ssc. wise.edu.

Ministry of Primary and Mass Education. (2010). Indigenous people's framework, promary education sector development program 3 (PEDP111): ADBTA no.7169-Ban. Dhaka: Government of the People's Republic of Bangladesh.

Nath, S. R., Yasmin, R. N., \& Shajamal, M. M. (2005). Out of school children in the tea gardens and ethnic minority communities. Dhaka: Bangladesh Rural Advancement Committee.

Nisbett, R. (1998). Race, genetics, and IQ. In C. Jencks \& M. Phillips (Eds.), The Black-White test score gap (pp. 86-102). Washington D. C.: Brookings Institution Press.

Nolan, B. (2000). A comparative perspective on trends in income inequality in Ireland. The Economic and Social Review, 31(4), 329350 .

Nsamenang, A. B. (2007). Cultures in early childhood care and education. Background paper prepared for the Education for All Global Monitoring Report 2007 UNESCO.

Ogbu, J. (1978). Minority education and caste: the American system in cross-cultural perspective. New York: Academic.

Ogbu, J. (1987). Variability in minority school performance. Anthropology \& Education Quertarly, 18, 312-334.

Ogbu, J. (1991). Minority responses and school experiences. Journal of Psychohistory, 18, 433-456.

Ogbu, J. (1994). Racial stratification and education in the United States: why inequality persists. Teachers College Record, 96, 264-298.

Ogbu, J. (2003). Black American students in an affluent suburb: a study of academic disengagement. Mahwah: Lawrence Erlbaum.

Ogbu, J. (2004). Collective identity and the burden of "acting white" in black history, community and education. The Urban Review, 36, 135.

Parsons, T. (1953). An revised analytic approach to the theory of social stratification. In R. Bendix \& S. M. Lipset (Eds.), Class, status and power: a reader in social stratification. Glencoe: Free Press.

Peek, P. (1979). The education and employment of children: a comparative study of San Salvador and Khartown. In G. Standing \& G. Sheehan (Eds.), Labor force participation in low income countries (pp. 177-190). Geneva: International Labor Office.

Rafi, M. (2006). Small ethnic groups of Bangladesh: a mapping exercise. Dhaka: Panjeree Publications Ltd. 
Rahaman, M. A. (2004). The Oraon community in Bangladesh and their socio-cultural attainments: a study of four villages. Rajshahi: Unpublished Ph.D. Dissertation, University of Rajshahi.

Rahman, M. A. (1984). Socio-economic problems of the Santal students studying in Rajshahi town. In M. S. Qureshi (Ed.), Tribal cultures in Bangladesh. Rajshahi: Institute of Bangladesh Studies, Rajshahi University, Bangladesh.

Rivera-Batiz, F. L. (2002). The socioeconomic status of Hispanic New Yorkers: current trends and future prospects. January 24, 2002. Available at www.pewhispanic.org.

Sakamoto, A., Goyette, K. A., \& Kim, C. H. (2009). Socioeconomic attainments of Asian Americans. Annual Review of Sociology, 35, 255-276.

Sarker, P. C. (1997). Social structure and fertility behaviour. Dhaka: Centre for Development Services.

Sattar, M. A. (1984). A comparison of age-sex patterns of participation in economic activities in tribal and non-tribal communities in Bangladesh. In M. S. Qureshi (Ed.), Tribal cultures in Bangladesh. Rajshahi: Institute of Bangladesh Studies, Rajshahi University, Bangladesh.

Sax, L. (2005). Why gender matters: what parents and teachers need to know about the emerging science of sex differences. Portland: Doubleday.

Sewell, W. H., \& Hauser, R. M. (1972). Causes and consequences of higher education: models of the status attainment process. American Journal of Agricultural Economics, 54, 851-861.

Sewell, W. H., \& Hauser, R. M. (1975). Education, occupation and earnings: achievement in the early career. New York: Academic.

Sewell, W. H., \& Hauser, R. M. (1980). The Wisconsin study of social and psychological factors in aspirations and achievements. Research in Sociology of Education and Socialization, 1, 59-99.

Sewell, W. H., Haller, A. O., \& Strauss, M. A. (1957). Social status and educational and occupational aspiration. American Sociological Review, 22, 67-73.

Sewell, W. H., Haller, A. O., \& Portes, A. (1967). Educational and occupational achievements of Wisconsin boys. Unpublished paper presented at meetings of the American Sociological Association (August).
Sewell, W. H., Haller, A. O., \& Portes, A. (1969). The educational and early occupational attainment process. American Sociological Review, 34, 851-861.

Sewell, W. H., Haller, A. O., \& Ohlendorf, G. W. (1970). The educational and early occupational attainment process: replications and revisions. American Sociological Review, 35, 1014-1027.

Siddiquee, A. R. (1984). Ethnicity and intelligence: a cross-cultural study. In M. S. Qureshi (Ed.), Tribal cultures in Bangladesh. Rajshahi: Institute of Bangladesh Studies, Rajshahi University, Bangladesh.

Sorokin, P. A. (1927). Social mobility. New York: Harper \& Row.

Sullivan, H. S. (1950). Conceptions of modern psychiatry. Washington D. C: William A. White Psychiatric Foundation.

Takenoshita, H. (2008). The economic incorporation of Brazilian migrants in comparative perspective: a comparative study of Brazilian labor maket outcome in Japan and United States. The paper presented at the conference of the International Sociological Association held at Stanford University, Stanford, California, the United States, 6-9 August 2008.

Toufique, K. A., \& Turton, C. (2002). Hands not land- how livelihoods are changing in rural Bangladesh. Dhaka: Bangladesh Institute of Development Studies.

Uddin, M. E. (2009). Cross-cultural socio-economic status attainment between Muslim and Santal couple in rural Bangladesh. International Journal of Human and Social Sciences, 4(11), 10791086.

Uddin, M. E. (2011). Cross-cultural social stress among Muslim, Hindu, Santal and Oraon communities in Rasulpur of Bangladesh. International Journal of Sociology and Social Policy, 31(5/6), 361-388.

Uddin, E. M. (2012). Cross-cultural social issues in rural Bangladesh. Saarbruchen: Lambert Academic Publishing.

van Oorschot, W. (2006). Culture and social policy: a developing field of study. International Journal of Social Welfare, 16, 129-139.

World Bank. (2000). Bangladesh: a proposal for rural development strategy. Dhaka: The University Press Limited.

Yetman, R., \& Steele, C. H. (Eds.). (1975). Majority and minority: the dynamics of racial and ethnic relations. Boston: Allyn \& Bacon. 